Quaestio facti. Revista Internacional sobre Razonamiento Probatorio Quaestio facti. International Journal on Evidential Legal Reasoning Vol. 1 | 2020 pp. $75-102$ Madrid, 2020

DOI: 10.33115/udg_bib/qf.i0.22364 Marcial Pons Ediciones Jurídicas y Sociales (C) Perfecto Andrés Ibáñez ISSN: 2604-6202

Recibido: 15/06/19 | Aceptado: 23/09/19

\title{
EN MATERIA DE PRUEBA: SOBRE ALGUNOS CUESTIONABLES TÓPICOS JURISPRUDENCIALES
}

\author{
Perfecto Andrés Ibáñez \\ La libertad está en las garantías \\ Filippo Manduca (1888)
}

RESUMEN: El autor discurre inicialmente sobre el porqué de la incorporación histórica de las garantías del imputado al proceso penal y sobre su papel fundamental en el desarrollo de este, como marco jurídico-constitucional de una actividad de carácter epistémico, en cuanto dirigida a obtener un conocimiento de calidad sobre algún hecho incierto prima facie penalmente relevante. Luego pasa revista críticamente a una serie de tópicos jurisprudenciales de cierto arraigo, que entran en contradicción con aquellas.

PALABRAS CLAVE: Proceso penal, garantías procesales, presunción de inocencia, nemo tenetur se detegere, prueba.

\section{REGARDING EVIDENCE: ON SOME QUESTIONABLE CASE-LAW CLICHÉS}

ABSTRACT: The author initially discusses both the reasons for the historical inclusion of the defendant's guarantees in the concept of due process of law and their fundamental role in terms of the development of this concept. The concept of due process embodies a legal and constitutional framework for an epistemic activity aimed at obtaining a quality knowledge about uncertain facts, which are prima facie considered criminally relevant. Moreover, the paper critically reviews a series of strongly ingrained case-law clichés, which appear to be inconsistent with those guarantees.

KEY WORDS: criminal procedure, due process of law, presumption of innocence, nemo tenetur se detegere, evidence. 
SUMARIO: 1. En el punto de partida.-2. ¿Qué superioridad de la jurisprudencia del tribunal supremo?-3. La naturaleza 'no fáctica' de la cara interna de la conducta.-4. Presunción de inocencia e in dubio pro reo.-5. ¿Elementos de prueba susceptibles de apreciación exclusivamente sensorial?.-6. la del testigo-víctima: ¿̨una prueba privilegiada?.-7. Acerca de la corroboración.—8. Sobre el valor probatorio de las actuaciones de la instrucción.-9. La llamada 'teoría' de la conexión de antijuridicidad o (casi) todo vale.

\section{EN EL PUNTO DE PARTIDA}

La vigente disciplina constitucional del proceso no podría comprenderse de una manera cabal, de no tomar en consideración los antecedentes que hicieron de gran parte de la historia de este un estremecedor catálogo de errores y horrores ${ }^{1}$. Por eso, es de toda pertinencia traer aquí la penetrante observación de Habermas (1988: 470), relativa a las modernas constituciones: «En la mayoría de los artículos dedicados a derechos fundamentales resuena el eco de una injusticia padecida que, por así decir, es negada palabra por palabra».

Quien discurra sobre los problemas del proceso penal con desconocimiento u olvido de esta perspectiva, estará, seguramente, condenado a no entender nada de la profunda razón de ser del proceso penal de inspiración constitucional y de las garantías procesales ${ }^{2}$. Del papel de las "precauciones tutelares» de Constant (1989: I, 250) que, si hoy reciben en los textos supranormativos el tratamiento de derechos fundamentales, no es por una frívola cuestión de estética o por algún ejercicio de narcisismo de juristas ensimismados o ilusos, enamorados de sus propias construcciones, que sería como decir de sí mismos. No, la cosa, en términos político-culturales, viene de lejos y desde muy hondo. Y el protagonismo y la responsabilidad de la correspondiente opción constitucional han sido, en los distintos, múltiples supuestos, de mayorías sociales abrumadoras en momentos de crecimiento democrático. Mayorías que sabían muy bien qué es lo que está en juego y, sobre todo, en riesgo, cuando no rige esta clase de previsiones, merced a una propia experiencia de los peores abusos... infligidos y padecidos durante siglos en nombre de la justicia.

Tal es la razón de la vigencia — jay! siempre precaria — de un proceso penal articulado en torno a la presunción de inocencia ${ }^{3}$, en su triple perspectiva: de principio

1 Ferrajoli, 1995: 603.

2 Resulta bien expresivo al respecto el, ciertamente anticipador, punto de vista de VERLANGa HuERTA (1842: 11): «las reglas del enjuiciamiento son leyes de seguridad pública, son las garantías del ciudadano en la sociedad, leyes dignas, por cierto, de figurar entre las que se llaman fundamentales, para las que ni aun el mismo legislador se atreva a sustituirlas con facilidad».

3 Y que, desde este punto de vista, está aquejado de problemas de legitimidad, incluso cuando su ejercicio pueda decirse correcto. Recuérdese la inquietante aporía, tan expresivamente denunciada por CARnelutti (1959: 75): «no solamente se hace sufrir a los hombres porque son culpables, sino también para saber si son culpables o inocentes. Esta es desgraciadamente, una necesidad, a la cual el proceso no se puede sustraer ni siquiera si su mecanismo fuese humanamente perfecto». Véanse también las consi- 
normativo central y estructural ${ }^{4}$, informador del proceso e ideal inspirador de las prácticas de los jueces penales en todo su recorrido ${ }^{5}$ (que, de apartarse de él, serían meros rituales burocráticos de castigo); de regla de tratamiento del imputado; y de regla de juicio. De ahí la relevancia del principio como principio ${ }^{6}$, que, en palabras de ILLUMINATI (1979: 80 y 84), implica toda «una opción de fondo", de una relevancia tal, "podría decirse — en abstracto- que, de no partir de la presunción de inocencia, no existiría ninguna necesidad lógica de proceso». Porque es, precisamente, la rigurosa exención al imputado del deber de demostrar su inocencia, la que demanda, con el mismo rigor, un proceso de tipo acusatorio y la renuncia a imponerle la condición de fuente de prueba contra sí mismo, y por eso su investidura del, igualmente fundamental, derecho al nemo tenetur se detegere ${ }^{7}$.

deraciones acerca de lo que Ferrajoli (1995: 10) llama "poder de disposición» del juez, frente al que las garantía (penales y procesales) representan un límite imprescindible.

4 «La afirmación de tal principio — escribe Illuminati (1979: 5) — si se entiende en su pleno significado, representa el eje del ordenamiento procesal moderno, puesto que están ligadas a él las más importantes garantías que tutelan, directamente, al imputado y, mediatamente, la corrección de la determinación [de los hechos]. El derecho a la defensa y al contradictorio, la inviolabilidad de la libertad personal, la reserva de jurisdicción y la imparcialidad del juez pueden, sin esfuerzo, verse resumidas en la presunción de inocencia del imputado, o en todo caso, encuentran en ella la motivación de fondo y el elemento unificador». Lucchini (1905: 15), discurriendo sobre el principio que nos ocupa, escribió: «que debe moderar y equilibrar el proceso a lo largo de todo su curso». UBERTIs (2000: 63) se ha referido a su dimensión "político procesal», que, entiende, constituye «un criterio informador y no solo un instrumento conjetural utilizado para la reconstrucción del hecho». Sobre esta condición de «la presunción de inocencia como principio informador del proceso penal», véase también FeRNÁNDeZ LóPEZ (2005: 119-123).

5 Es de toda evidencia que de la intensidad de la asunción y del compromiso con la presunción de inocencia como principio, dependerá la calidad de la impregnación constitucional de las prácticas de jueces y fiscales. Del criterio en materia de admisión de pruebas, al modo de dirigir los interrogatorios, al uso de la prisión provisional y a la justificación de las decisiones limitadoras de derechos, son multitud los actos y los momentos del proceso en los que el perfil de la actividad hablará con patente locuacidad al respecto. Puedo asegurarlo por una dilatada experiencia en el ejercicio de la jurisdicción penal en, prácticamente, todas las instancias.

6 Para Valiante (1975: 180), que toma la expresión de la sentencia de la Corte Constitucional italiana n. ${ }^{\circ} 33 / 1959$, de 12 de mayo: "Principio [...] de civilidad", [que] debe convertirse en posición cultural, regla de costumbre, norma de comportamiento para todos y especialmente para quienes tienen responsabilidades de formación y orientación. El discurso vale especialmente para la escuela y para la prensa».

7 Filangieri (2018: 1. III, cap. X, 663) consideró lúcidamente la confesión del imputado «un imposible moral», la aserción del que se halla «en la misma disposición de un suicida». Mucho más próximo a nosotros, Calamandrei (1952: 239) escribió: «Yo pienso que cuando se parte de la premisa de que existe una verdadera y propia obligación jurídica del imputado de decir la verdad y se niega que exista a su favor un derecho al secreto o al silencio, comprendido entre los derechos de libertad, de seguirse el hilo lógico, tal afirmación lleva a legitimar la tortura». Este punto de vista tiene la más acreditada confirmación en la añosa experiencia del imputado detenido que, en la policía, es objeto de una suerte de concienzudo work in progress que, al fin, desemboca en una (previsible) declaración autoinculpatoria. Un curso, tan asumido como regular por los policías, los fiscales y — jay! — no pocos jueces, que, con frecuencia, se registra en los atestados con la mayor naturalidad. Así, se deja constancia de un primer momento en el que aquel manifiesta su propósito de no declarar, pero de que, al fin, acaba haciéndolo voluntariamente, incluso con llamativa locuacidad, al término de la detención. Y no se diga, 
Se trata, en efecto, de una opción de fondo que, en esa dimensión profunda, conecta con un básico compromiso (consigo mismo y con la ciudadanía), del estado constitucional, en la materia. Es el que se concreta en la exigencia de que la aplicación del ius puniendi — tan abierto a usos abusivos como se sabe- para ser legítima ${ }^{8}$, vaya asociada a la previa determinación de una verdad fáctica de calidad, siguiendo un curso procesal que, inexcusablemente, deberá discurrir dentro de un exigente marco de garantías jurídicas. Y por eso, o lo que es lo mismo, por una elemental razón de coherencia interna del modelo, el derecho del imputado a la presunción de inocencia únicamente podrá decaer en presencia de prueba de cargo suficiente para enervarlo, pero solo si lícita o regularmente adquirida ${ }^{9}$. Esto, también, porque en la memoria del ordenamiento constitucional está activo el recuerdo de los masivos usos aberrantes del proceso penal ${ }^{10}$, frente a los que el vigente sistema quiere ser un efectivo detente, un «nunca más». Porque en él late, constitucionalizada, la conciencia de que "“administrar justicia penal” significa cambiar vidas» (ANónimo, 2019: 14); y la evidencia de que "con excepción de la guerra, históricamente acaso el poder más salvaje de todos ha sido el poder punitivo» (Prieto Sanchís, 2011: 13).

cuando esta resulta prorrogada en aplicación de legislaciones como la antiterrorista. En una impactante sentencia de estos años, de la Sección Segunda de la Audiencia Nacional (ponencia de Enrique López) se habla de «una cierta presión policial, que sin estar cerca ni por asomo a la tortura, va ínsita al mero hecho objetivo de estar privado de libertad varios días en un centro de detención, sometido a constantes interrogatorios, donde obviamente se recoge el prestado finalmente ante abogado». (¿Cómo no sentir nostalgia de Miranda vs. Arizona?). Acerca de este principio, en la rica complejidad de sus implicaciones, sigue siendo fundamental la clásica obra de Grevi (1972) recogida en la bibliografía.

$8 \mathrm{Y}$ ya se ha visto que nunca lo será del todo. Y no solo por los márgenes de apreciación de que disponen jueces y fiscales, sino por las más que cuestionables formas de uso político del proceso penal, tantas veces reflexiva e inaceptablemente cargado de finalidades sustantivas por el legislador mismo. Por no hablar de la incontenible prodigalidad de la que este último suele hacer gala en el empleo del derecho penal, por ello, en tantos casos, no última sino más bien única ratio. Para una propuesta de racionalización del uso del ius puniendi, frente al actual modo de proceder con él, véase la obra de PASTOR (2005) citada en la bibliografía.

9 Las ilicitudes probatorias por razón de la vulneración de algún derecho fundamental, sustantivo o procesal, con su secuela de inutilizabilidad de la información de cargo mal adquirida, han concentrado también la enemiga de los que disparan, en general, contra la presunción de inocencia y las garantías procesales que son su implicación. Y se entiende, porque su adecuada valoración reclama una sensibilidad que, desgraciadamente, no abunda. En particular exige entender que el estado constitucional, consciente de lo demoledora que resulta la utilización del ius puniendi para los afectados (por no hablar de la objetiva desigualdad que la distingue), ha decidido circunscribir su uso dentro de precisos márgenes, como condición sine qua non de legitimidad. Y, tomándose a sí mismo en serio, ha obrado como ya sugería CARRARA (1976a: II, 37): «Si las formalidades impuestas a la instrucción no se ordenan bajo pena de nulidad, sería una insulsa irrisión haberlas decretado».

${ }_{10}$ Que en este punto no pueden decirse desterrados, por la incontenible tendencia de las policías de la generalidad de los países a operar por debajo de los estándares legales (no se diga constitucionales) en la obtención de fuentes y medios de prueba; y de los jueces y tribunales a situar el principio de conservación de los actos (sobre todo si de efectos inculpatorios), por encima de cualquier previsión o consideración legal. Lo que, con alarmante frecuencia, se traduce en conferir un marchamo de legitimidad a prácticas profesionales de pésima calidad, eso sí, productivas a los fines de la incriminación y la condena. 
No haría falta decirlo, pues es un dato de conocimiento común, que el principio de presunción de inocencia con su corolario al que acaba de aludirse, ha suscitado desde antiguo, como suscita, la incomprensión y la enemiga de las policías y los ministerios del interior, adictos a las políticas criminales (tómese la expresión en su literalidad) «de ley y orden», tan caras a las derechas, y más cuanto más extremas. También, por cierto, ha contado con valedores en el ámbito de la teoría, en la estela de JаковS (2003), para quien el que no se hiciere acreedor del status civitatis a través del regular cumplimiento de los deberes que impone el ordenamiento, «si se comporta permanentemente como un diablo, se convierte en un enemigo, es decir, en una no-persona» ${ }^{11}$. El tópico argumento justificador de semejante opción es el de un cierto eficientismo represivo, productivista sin principios, que buscaría poner coto a una impunidad, supuestamente generada, por la constitucional observancia del de presunción de inocencia, con sus implicaciones ${ }^{12}$. En tal inaceptable planteamiento, se trataría de resucitar el ídolo de la Verdad material (con mayúscula), siempre ávido de sacrificios humanos; de propiciar el acceso a la identificación del materialmente culpable ${ }^{13}$, sorteando el obstáculo de unas garantías procesales de relieve constitucional, que tan disfuncionalmente se interpondría entre aquel y el $(\mathrm{ya})$ merecido castigo $^{14}$. No parece descabellado pensar que el Pedro de Castro (2009: 128) de «la sospecha justa es punible» se reconocería, feliz, en estos planteamientos.

Pero semejante modo de discurrir yerra el tiro, pues las bolsas de impunidad de mayor relevancia, incluso de dimensiones estratosféricas, que realmente coexisten en la sociedad desigual ${ }^{15}$ con, mejor, al margen del sistema penal, no tienen nada

11 Críticamente, sobre el punto de vista de Jakobs, véase Ferrajoli (2006: 3 ss.); también Prieto SAnchís (2011: 68 ss.).

12 Para un argumentado y convincente punto de vista crítico en la materia, cfr. Ramírez OrTiz (2014: 18 ss.) y GUZMÁN (2018: 85 ss.).

13 Ubertis (2017: 108-109) asocia esta categoría a la epistemología inquisitiva, que se sirve — dice- de la "pantalla de la "verdad material" " para justificar "limitaciones del derecho de defensa y la elusión de reglas probatorias de garantía». Como bien explica Ferrua (2012: 51), «la prueba de la culpabilidad se obtiene solo dentro del proceso", de ahí que la verdad (procesal) al respecto solo pueda ser formal, en cuanto obtenida en un marco de reglas; de donde se sigue la imposibilidad, el absurdo lógico, de hablar —en este contexto, ¿con qué fundamento?- de un materialmente culpable; como si se tratase de una suerte de objeto con existencia real susceptible de ser legítimamente descubierto de algún otro modo.

${ }_{14}$ En una mesa redonda sobre cuestiones probatorias, celebrada en la Corte Suprema de Perú en 2018, uno de los intervinientes, cual si se tratase de un desafío teórico, planteó el supuesto de que la hipótesis acusatoria no hubiese resultado acreditada, pero, no obstante, fuera la más probable, sugiriendo que de esto tendría que derivarse alguna conclusión, obviamente, sancionadora. Me pareció pertinente recordar que, como resulta de las obras de Claro, Menochio, Carpzov y otros, en los siglos xvi y XVII, ya estaba en uso la poena extraordinaria, de discrecional aplicación al arbitrio del juez, en los casos de existencia de una semiplena probatio. Acerca de este instituto pueden verse: MecCARELli (1998: 195 ss.) y Alessi Palazzolo (1979: 43-45).

15 «La justicia es igual para todos, las sentencias, no», reza el pie de una viñeta de El Roto, en El País (23 de febrero de 2017). El gran humorista discurre así, muy expresivamente, sobre cómo la jurisdicción penal se proyecta de formas altamente diferenciadas, a tenor de los estratos sociales de procedencia de los usuarios. 
que ver con la aplicación del principio de presunción de inocencia. Paradigmático al respecto es, precisamente, el caso de Estados Unidos, uno de los países del conocido como primer mundo, donde más graves padecimientos experimenta aquel en el caso del imputado estándar ${ }^{16}$, que, al mismo tiempo, arroja la evidencia de estremecedoras cifras porcentuales de impunidad. Referidas, claro, a conductas criminales de infractores excelentes, de enorme gravedad y muy negativa trascendencia social, que nunca llegan al juzgado ${ }^{17}$. Pero, eso sí, que nada tienen que ver con la delincuencia común convencional, generalmente tratada con los expeditivos procedimientos de la justicia "negociada». La justicia sin juicio made in USA ${ }^{18}$, basada en una contratación —adhesiva para el acusado— sobre la culpabilidad y/o la pena ${ }^{19}$; que, como advirtiera SchünEMAnN (1991), protagoniza desde hace años una muy preocupante «marcha triunfal» por el mundo, con la complicidad de no pocos juristas, jueces y fiscales. Este inaceptable modo de operar produce sentencias condenatorias sin proceso a escala industrial ${ }^{20}$; y, en tal sentido, presta un eficacísimo servicio en términos de masivo control social, sirviendo al mismo tiempo para deflacionar el proceso penal.

16 Si hiciera falta — diría que no, tratándose de juristas con alguna sensibilidad y razonablemente informados - la experiencia de Innocence Project, es bien ilustrativa al respecto. Interesantísimo y muy revelador en la materia es también el libro de STEVENSON (2014) citado en la bibliografía.

17 Para un penetrante, documentado y consistente abordaje crítico de este asunto en sus diversos perfiles, remito a ТАІвBI (2015), que discurre, sobre la base de una consistente información, acerca de lo que el editor califica de "curioso misterio estadístico», que es el representado por la expresiva conjunción de tres factores: que la pobreza aumenta, el crimen disminuye y la población reclusa se duplica. Al que habría que añadir otro, también fruto de la experiencia de estos años, fundamental para adverar el argumento que motiva esta nota. Y es que el fraude de los agentes económicos responsables de la reciente crisis, que arrambló con el cuarenta por ciento de la riqueza mundial, ha pasado sin consecuencias para ellos, a pesar dl mismo ТАгвві (2015: 378): «Si en las barriadas de vivienda protegida se ha impuesto un estado policial, en Wall Street ha ocurrido justo lo contrario. Una mentira en San Diego es un crimen. ¿Un millón de mentiras? Un buen negocio».

18 Es desolador el juicio de FAsin (2018: 32): «se estima que de los dos millones doscientos mil presos en Estados Unidos, más de dos millones están encarcelados sin haber tenido derecho a un proceso". Por eso lo pertinente de traer aquí el juicio de WinsLow (2019: 286): «Según el estilo de vida americano, puede que la verdad y la justicia se saluden por el pasillo, que se envíen una tarjeta de felicitación por Navidad, pero esa es toda la relación que mantienen».

19 Sobre estas prácticas en un juzgado de Brooklyn, acerca de las que el autor ha hecho un verdadero trabajo de campo, ТАІвві (2015: 133) escribe: "Estiro el cuello para intentar ver qué está pasando, y lo único que veo es que la defensa, la fiscalía y el juez han formado un corro y están negociando. Alguien farfulla al micrófono: "Su supervisora aceptará redención de prisión preventiva y quebrantamiento de la condicional". A continuación, hay gestos de aprobación por toda la sala y, de repente, igual que cuando los jugadores de rugby deshacen el corro, todas las partes se retiran a sus puestos. Suena la maza del juez y se llevan a la acusada que asiente, aunque siga con los ojos cerrados. Está conforme con el acuerdo». Resulta inevitable relacionar esta descripción con la de una experiencia del género descrita en su día por Wolfe (1988: 108 y 118), que sitúa la acción en un juzgado del Bronx neoyorkino. En la materia, cfr. al respecto la obra de Pizzi (1999: 102-104), también: Ferrua (2017: 20 ss.); Armenta Deu (2012: 128 ss.); Gascón Abellán (1999: 127-128); y Andrés IbáÑez (2007a: 222 ss.).

20 Como también denuncia Fasin (2018: 31-32), sentencias negociadas, en un elevado porcentaje, condenatorias de inocentes que, en la imposibilidad de disfrutar de una defensa eficiente, acaban pactando con el fiscal por motivos exclusivamente pragmáticos. Sobre este tipo de casos, situando la acción en Francia, ha discurrido con fortuna, en clave de narrativa, Postel (2014). 
El derecho a la presunción de inocencia, en su versión ilustrada y liberal, —cuestión de urgencias - circunscribía esencialmente su radio de acción a la finalidad de evitar al imputado el brutal tratamiento de presunto culpable deparado por el proceso penal ancien régime. Así, haría falta algún tiempo para llegar a extraer de aquel todas sus restantes potencialidades. A algunas, primeras en el orden temporal, se ha aludido sucintamente ya en lo que precede, pero, diría, la última en comparecer en la escena, superado, sobre todo en el plano teórico, el criterio de libre convicción como intime conviction ${ }^{21}$, es la que ha visto en el principio una consistente implicación de método, más concretamente, epistémica ${ }^{22}$. En efecto, porque este demanda del juez o tribunal una posición neutral, de duda seriamente asumida, en el punto de partida frente al caso; la reflexiva adopción de la actitud de «perplejidad» que reclamaba Muratori (1794: 79); ese poner la conciencia, como quería Calamandrei (1960: 89), en modo "página en blanco» ${ }^{23}$, para empezar a saber, solo, en un marco procesal efectivamente regido por el principio de contradicción. Y saber, no en virtud de un pálpito o por iluminación, sino como metodológicamente corresponde, cuando se trata de obtener conocimiento empírico de calidad sobre hechos singulares.

Dicho de la manera más simple, en presencia de un problema, en realidad duda acerca de un hecho incierto (que interpela al derecho penal), en una primera fase, se tratará de conjeturar, de formular alguna hipótesis sobre lo eventualmente acontecido, de evaluarla provisionalmente en su calidad explicativa a tenor de los datos en presencia; para, si efectivamente funciona y cuenta con suficiente apoyo en pruebas, darle el tratamiento formal de acusación. Trasladándola, en ese caso, como tal, al ámbito del enjuiciamiento, para someterla a comprobación con las demás concurrentes, esto es, hacerla objeto de debate «con paridad de armas» ante un juez o tribunal imparcial, que deberá decidir motivadamente ${ }^{24}$. Es decir, tomando en consideración la totalidad de las aportaciones probatorias, verificando, a tenor de estas, cuál de las hipótesis a considerar es —en su caso_ la única que las integra de la forma más coherente y permite llegar a una conclusión, no solo argumentalmente fundada con el rigor exigible, sino también plausible ${ }^{25}$.

21 En la materia sigue siendo de imprescindible consideración la ya clásica obra de NoBili (1974).

22 La ausencia de esta perspectiva resulta patente, por ejemplo, en Florian (1982: I, 391), que expresivamente escribe: «fuera de ese sistema [de prueba legal], cualquiera que sea el alcance de la presunción de inocencia, cualquiera que sea el criterio general que rija el proceso, dicha presunción [la de inocencia] no tiene por qué regular apriorísticamente las pruebas». Lo mismo puede decirse de Malatesta (1988).

${ }^{23} \mathrm{Al}$ respecto, ha escrito IACOviello (1997: 139): «la indagación cognoscitiva del juez parte de la duda, no de la ingenuidad [...] el juez que entra en el juicio oral no es un juez ingenuo, sino un juez dubitativo. Un juez que se encuentra en la mejor situación epistemológica posible».

${ }^{24}$ Aquí se ha de tener en cuenta que la motivación de la sentencia, que opera como justificación de la decisión, una vez adoptada; en rigor, habrá debido operar ex ante, bajo la forma de una asunción intelectualmente honesta del correspondiente deber constitucional por parte del juez o tribunal, llamado a producir el efecto imprescindible de que el discurso probatorio se mantenga rigurosamente, en todo su desarrollo, dentro de lo que sea susceptible de justificación. Me he ocupado de este asunto en ANDRÉs IBÁŃEZ (2007b).

25 «La motivación — ha escrito TARuffo (2002: 436) — debe dar cuenta de los datos empíricos asumidos como elementos de prueba, de las inferencias que partiendo de ellos se han formulado y 
Este modelo y el correspondiente modus operandi, de ser llevados a la práctica con la corrección requerida, creo que puede asegurar un tratamiento epistémicamente muy estimable de la quaestio facti y, por tanto, el acceso por vía procesal a esa verdad de calidad, que es ineludible presupuesto de la justicia de la decisión judicial. Ahora bien, en este punto, es preciso señalar que, en el desarrollo del razonamiento probatorio, la duda — como hábito intelectual del juzgador - actuará cual factor de dinamismo y de estímulo hacia el cuestionamiento y la problematización, imprescindibles, de las alternativas en presencia, para dotar a ese curso intelectual de la necesaria racionalidad. Pero en el momento central del cruce de la información adquirida y de la valoración de síntesis para concluir, aquella debe operar como una llamada a la autocontención y a la prudencia, como una especie de freno, en el sentido de que dudar significará la inexistencia de duda, debiendo ser la absolución la única salida.

En una constitucional perspectiva, esto es, la que integre en su unidad/distinción las dos dimensiones (jurídica y epistémica) del enjuiciamiento, cuando la incoación del proceso haya respondido realmente a la existencia de indicios de delito intersubjetivamente valorables, y su desarrollo se haya producido conforme a las reglas que rigen en ambos planos, la absolución dotada del necesario razonable fundamento, nunca será expresiva de un quiebra sino, más precisamente, del fisiológico funcionamiento del sistema. Que, a diferencia del inquisitorial y el inquisitivo, no cifra su éxito, de manera exclusiva, en la obtención de condenas (y, menos aún, de cualquier condena), ni valora todo fracaso de una imputación como factor de impunidad ${ }^{26}$. Y es que, en este terreno, es decir, el del ordenamiento kelsenianamente leído como se debe, a partir de la primera norma: hay un momento incancelable, en el que la cosa va prioritaria y sustancial, si no exclusivamente, de derechos fundamentales.

En lo que sigue se pasará revista a algunos tópicos presentes en la jurisprudencia penal española de años, que, en general, no han perdido toda su vigencia, a pesar de hallarse en una clara relación conflictual con el planteamiento que acaba de desarrollarse.

\section{2. ¿QUÉ SUPERIORIDAD DE LA JURISPRUDENCIA DEL TRIBUNAL SUPREMO?}

En rigor procesal y en buena cultura de la jurisdicción hay que decir que los tribunales supremos, cortes de casación o como quiera que se los denomine, derivan

de los criterios utilizados para extraer sus conclusiones probatorias; del mismo modo, la motivación debe dar cuenta también de los criterios con los que se justifica la valoración conjunta de los distintos elementos de prueba, así como de las razones que fundamentan la elección final para que la hipótesis sobre el hecho esté justificada» Cfr. en este punto las útiles indicaciones de método que proporciona FERRER (2007: 147 ss.).

26 Lo expresó muy bien CARrara (1976a, II: 279-280): el «verdadero escándalo» no lo ocasionan las sentencias absolutorias dotadas de fundamento legal, sino las condenatorias «precipitadas [fundadas] en falaces argumentos». 
su superioridad del solo hecho de ser los últimos en decidir, ya que por motivos de seguridad jurídica las causas no pueden permanecer indefinidamente abiertas. Pero lo cierto es que el carácter generalmente piramidal de las organizaciones judiciales, ha producido el histórico efecto de superponer al rango meramente procesal de la cadena de instancias otro de naturaleza jerárquico-administrativa, con el resultado de conferir a los tribunales-vértice de la organización una supremacía de ese carácter; en rigor, de calidad extrajurisdiccional, por tanto. Es lo que ha permitido a los órganos de referencia dotar a sus resoluciones de cierto plus de imperatividad, que así no guardaría relación directa con la calidad del contenido y ni siquiera con el rol procesal de la casación, al traer causa de ese factor no-jurisdiccional representado por su posición de poder más bien político, o jerárquico-judicial, si se quiere. De donde el precedente sería vinculante, no tanto y no solo por razón de auctoritas, sino de cierto imperium, de fuente, insisto, no jurisdiccional en sentido propio.

Esta suerte de extrapoder jurisdiccional atípico, tiene precedentes históricos, por ejemplo, en las facultades autoatribuidas por los grandes tribunales europeos del ancien régime, cuando, aún plenamente vigente el sistema de prueba legal, se arrogaron la potestad de decidir con libertad según la propia convicción, algo que no permitían a los inferiores ${ }^{27}$. «Non tenetur iudex causam in sententia exprimere, maxime si sit supremus magistratu", porque, como escribiera MAYNARD, citado por AjELlo (1976: 341), con referencia al Parlement de Toulouse, este juzgaba «en souverainetée ${ }^{28}$. En idéntica línea de constatación de ese modo de operar, Thomasis, asimismo citado por Ajello (1976: 342), explicó que «los primeros tribunales de Europa tenían a gloria poder decidir según equidad y no a tenor de la ley y prescindir de las formalidades del juicio».

Pues bien, no me parece exagerado afirmar que en la actual idea de jurisprudencia de los altos tribunales contemporáneos pervive, puede que de forma más discreta, cierto sentido del disfrute de alguna prerrogativa, por razón del rango.

Pero hay que subrayar que la jurisprudencia, en contra de lo que tópicamente suele creerse, es y no puede dejar de ser un resultado coral, en cuya producción intervienen muchas voces, que, cualquiera que sea su lugar en la geografía orgánica, interactúan y se relacionan dialécticamente, de forma que la obra final es necesaria y objetivamente cooperativa. Se da, además, la circunstancia de que ni siquiera tie-

27 «Los grandes tribunales europeos (los Parlamentos en Francia, los Senados, las Rotas, los Supremos Consejos, las Grandes Cortes) se atribuyeron, como es sabido, una libertad de valoración mucho mayor que la de los jueces menores» (RosonI, 1995: 209). "Los tribunales superiores [...] se consideraban libres de los límites de una estricta legalidad, y teorizaban la posibilidad de juzgar secundum conscientiam", algo negado a los jueces inferiores (Alessi Palazzolo, 1979: 30).

28 «En soberanía», un planteamiento que contrasta con el del juez COKE, invocando «la razón artificial y el juicio acerca de lo que es el derecho», en temprana defensa de la iurisdictio frente al gubernaculum, personalizado, en la famosa anécdota, por Jacobo I (Pound: 73-74). Curiosamente, cuando el estado de derecho ha desplazado a la suprema potestas, todavía se sigue hablando de «soberanía» para referirse a cierta omnímoda libertad de apreciación del juzgador en el caso de las pruebas personales practicadas ante él con inmediación. 
ne buen fundamento real el tópico de que la mayor contribución procede siempre y como por definición del vértice. De un lado, porque es en la primera instancia donde suelen fijarse las situaciones justiciables, predeterminando en gran medida el tratamiento jurídico final del caso. Y, de otro, porque, a tenor de los criterios de selección imperantes, tampoco podría siquiera sostenerse que el mayor y mejor nivel de conocimientos esté, por sistema, en la cúspide de la pirámide escalafonal. A la que tampoco corresponde necesariamente la parte más difícil del quehacer jurisdiccional.

Ninguna de estas afirmaciones quita un ápice de relevancia a la función de los tribunales de casación. Tienen, desde luego, la que resulta del hecho de que hablan autoritativamente en último lugar, decidiendo por lo general de modo inapelable. También la esencial, pedagógica, de la posibilidad de proponer, desde su altura procesal, al más amplio auditorio, cuando las sentencias se cargan de razón, una forma ejemplar de abordar y resolver con racionalidad los conflictos jurídicamente más significativos. Pero una adecuada caracterización de la jurisprudencia como fenómeno jurídico-institucional, no puede perder de vista que es el resultado final de muy plurales aportaciones, de actores que deben gozar de independencia interna para operar con exclusiva sujeción a la ley y a criterios de racionalidad cognoscitiva. Por eso, una jurisprudencia que negase o limitase de cualquier modo la proyección empírica de ese principio central de la jurisdicción, haría entrar a esta en inevitable conflicto consigo misma.

Con todo, es obvio, la jurisprudencia de casación no puede dejar de irradiar desde el vértice. Pero, en buena ley, por un solo motivo, ahora de naturaleza jurídicoprocesal (y no jerárquico-burocrática): el de ser ese tribunal el competente en exclusiva para el ejercicio de la función nomofiláctica, en cuyo desempeño, ciertamente importante, no cabe sustitución. Tal cambio de fundamento en la lógica del sistema demanda otro de cualidad en la interacción, es decir, en el modo de ser de la relación entre instancias que, a salvo la habilitación de aquel para decir la última palabra, debe ser esencialmente dialógica y bien argumentada, porque es lo que corresponde a una función de carácter cognoscitivo como la jurisdiccional. Así, el flujo de los criterios jurisprudenciales, en una consideración externa y meramente formal, será vertical, de arriba abajo. Pero en su elaboración deberá prevalecer una dinámica tendencialmente horizontal, la propia de una racional y abierta confrontación de razones que, en cuanto tales, no saben de rangos protocolarios ni de jerarquías administrativas.

\section{LA NATURALEZA 'NO FÁCTICA' DE LA CARA INTERNA DE LA CONDUCTA}

Hay un supuesto, protagonizado en su día por la Sala Segunda del Tribunal Supremo, documentado en la sentencia de 7 de abril de 1902, en el que, a fin de ampliar el espectro del conocimiento en casación al elemento del delito representado por el ánimo de engañar, en la estafa, decidió que no era un dato fáctico (que lo haría inabordable en esa instancia), por «no pertenece[r] a la esfera de los sucesos reales 
perceptibles por los sentidos, sino una mera deducción de carácter jurídico» fiscalizable, por tanto en el ámbito de la infracción de ley (Aguilera de Paz, 1924: V, 558).

El Tribunal Supremo, que nunca podría dictar una ley, sí se consideró (y ha seguido considerándose) legitimado para decidir — ¿en souverainete? — sobre la naturaleza, fáctica o jurídica, de los fenómenos. También, incluso, para resolver carrolianamente sobre (en este caso, mejor, contra) el sentido que las palabras tienen en el diccionario, tratando como deducción lo que sería clara expresión de un modo inductivo (o abductivo) de razonar, como el empleado para derivar un enunciado particular de otro u otros enunciados del mismo carácter, con el auxilio de una máxima de experiencia: que es lo que se hace para determinar la existencia de un cierto animus.

El aludido modus operandi, movido seguramente — in bonam partem - por el propósito de evitar arbitrariedades como la que podría haberse producido con la absolución por la Audiencia del acusado en la causa a que dio lugar la sentencia citada, adquirió verdadera carta de naturaleza en la jurisprudencia de la Sala Segunda. Hasta el punto de que ha mantenido su vigencia incluso después de la introducción constitucional del principio de presunción de inocencia como regla de juicio, que implica la franca asunción de un paradigma de método centrado en la inducción probatoria. A ello se debe una abundantísima jurisprudencia fundada en la inaceptable consideración de los factores intencionales (la cara interna) de la conducta como algo esencialmente distinto de la forma exterior de esta. Tal es lo que justificaría el aserto, mil veces reiterado, de que la intención o el animus son «no hechos» sino «juicios de valor», puestos en la escena procesal por el juzgador que, por eso tendría que ubicarlos dentro de la sentencia, en el área los fundamentos de derecho. Dado ese carácter, es el último tramo del discurso - como se ha podido leer en muchas sentencias e informes del fiscal-, aquellos «no pueden ser objeto de prueba, ni entran en el ámbito de la presunción de inocencia» ${ }^{29}$. Esto, en virtud de un presupuesto, el de que solo es susceptible de prueba aquello que puede percibirse por los sentidos. Lo demás se infiere. Cual si existiese un modo de operar/discurrir con/sobre las aportaciones probatorias que no fuera el inferencial. Como si, por poner un ejemplo banal, resultase posible dar cabal cuenta de la acción de alguien de disparar sobre otro, prescindiendo de su intención ${ }^{30}$, de no ser al precio de introducir en ella el cambio de cualidad consistente en convertirla en una conducta inanimada. Que es lo sucedido de forma absurda en tantísimos relatos de hechos probados, a lo largo de más de un siglo.

El punto de vista que acaba de exponerse ha reinado de forma incontestable en la jurisprudencia penal de nuestro país. Tanto es así que, solo en años muy recientes, semejante canon comenzó a ser desplazado de algunas sentencias cuestionadoras de

29 «Los elementos objetivos del delito, [...] son los únicos sobre los que puede versar la actividad probatoria en sentido estricto, quedando fuera de su órbita los elementos subjetivos, por constituir estos verdaderos juicios de valor o inferencia, como actualmente se prefiere, más correctamente, denominarlos» (Luzón Cuesta, 2000: 57).

30 Lo expresó muy bien Devis Echandía, H., (1981: I, 163-164): «No se trata de hecho materiales, pero sí de hechos reales, susceptibles de conocimiento concreto" por lo que, obviamente, "pueden ser objeto de prueba judicial». Cfr. también ANDRÉs IbáŃEZ (1992). 
esa visión demediada de lo fáctico, así como de la fragmentación de su tratamiento en lo que se refiere al principio de presunción de inocencia como regla de juicio y opción de método. Aquel criterio, que no diría decididamente abandonado, se ha ido batiendo lentamente en retirada, con escala en una curiosa etapa intermedia: la representada por algunas sentencias en las que los elementos de referencia aparecían dotados de una peculiar naturaleza mixta o jurídico-fáctica.

Por tanto, es de una obviedad inobjetable que el derecho a la presunción de inocencia como regla de juicio debe presidir el tratamiento de la prueba de lo fáctico en toda su extensión, y sea cual fuere el objeto de la misma.

\section{PRESUNCIÓN DE INOCENCIA E IN DUBIO PRO REO}

En materia de presunción de inocencia existe también otra falacia sumamente arraigada, que tiene su origen en la jurisprudencia del Tribunal Constitucional, y se ha impuesto, no, obviamente, por su racionalidad, sino por la vía del rango de esta instancia. Es la que se concreta en la atribución al principio in dubio pro reo de cierta autonomía conceptual respecto del de presunción de inocencia ${ }^{31}$. Este jugaría de manera exclusiva en los supuestos de riguroso vacío probatorio, y aquel en el resto de los casos, es decir, siempre que hubiese alguna prueba susceptible de apreciación. Determinando relevantes consecuencias de orden competencial en materia de recursos.

Si se presume la inocencia, sólo cabrá atribuir la condición de autor del delito a un imputado cuando exista certeza probatoria de que, en efecto, lo ha sido. Así, la certeza práctica de esta clase, es la única llave que puede franquear al juzgador en su discurso la puerta de salida del recinto de la presunción de inocencia y el acceso al de la incriminación. La duda al respecto no goza de tal virtualidad, luego la conducta sobre la que se proyecte permanecerá, mientras esta subsista, dentro del ámbito cubierto por aquella, de la que el de in dubio pro reo es la más obvia implicación. En efecto, pues, si tras de la valoración de la prueba en su conjunto, resulta forzoso absolver en caso de duda, es solo porque se parte de la inocencia como principio. Lo que hace que todo elemento o momento de incertidumbre sobre la hipótesis de la acusación lleve necesariamente a excluirla.

De este modo, es claro, la pretensión de autonomía conceptual del principio in dubio pro reo frente al de presunción de inocencia resulta rigurosamente inaceptable, pues todo lo que no sea acreditada culpabilidad queda comprendido en el ámbito de esta última, cuya afirmación definitiva después de un juicio deberá ser incondicionada. Si se parte de la presunción de inocencia como presupuesto, el fracaso probatorio

31 Lo que hay detrás de este planteamiento, introducido por el Tribunal Constitucional, es la necesidad práctica de establecer un filtro en el acceso al recurso de amparo, reservándolo para los supuestos de inexistencia de prueba, con objeto de hacer más manejable su agenda. Una necesidad real, a tenor de la estadística, pero a la que tendría que hacerse frente por otras vías, y de la que en modo alguno pueden extraerse conclusiones de orden conceptual. 
de la hipótesis de la acusación sólo puede confirmar el estatus de inocencia preexistente. Lo contrario llevaría forzosamente a consagrar la existencia de una absolución plena por inexistencia de pruebas y otra solo por insuficiencia de estas, y, como consecuencia, a establecer categorías de inocentes.

A partir de estos presupuestos, se hace insostenible la aludida distinción jurisprudencial al uso entre casos atinentes al principio de presunción de inocencia y casos relativos al principio in dubio pro reo, aquellos fundados, como se ha dicho, en la ausencia (objetiva) de prueba, y estos en la existencia de alguna susceptible, pues, de valoración (subjetiva, por tanto). Tal cuestionable criterio parece sugerir también la existencia de algún modo de apreciación de la calidad acreditativa de lo aportado por los medios de prueba, que operaría sin necesidad de entrar en su evaluación. Cual si estos probasen, se mostrasen como tales en su efectividad por el mero enunciado. Cuando lo cierto es que no prueban por sí mismos, por autoevidencia, sino que existirán, como medios de prueba - que prueben, que es lo que cuenta- en un contexto y por la apreciación judicial. De este modo, predicar algún potencial probatorio de un determinado medio es un acto de atribución de esa propiedad, que exige valoración y no simple constatación de una presencia. Incluso en la fase procesal de admisión, la correspondiente decisión judicial no será el mero fruto de la observación elemental que parece sugerirse, sino la conclusión de síntesis de un razonamiento de cierta complejidad sobre la naturaleza de la fuente de información y de una estimación de su hipotético, eventual rendimiento ${ }^{32}$.

Otro tanto ocurre, por ejemplo, en materia de recurso de amparo, cuando se trate de verificar si en la instancia jurisdiccional ordinaria concurrió o no la tópica «mínima actividad probatoria» ${ }^{33}$ de que habla la jurisprudencia. Una determinación

32 Sobre la naturaleza del juicio de relevancia, es imprescindible remitir a TARUfFo (1970, 231 ss.).

33 "Mínima actividad probatoria», frente al vacío de prueba, es el criterio de demarcación utilizado por el Tribunal Constitucional para decidir sobre la admisión de las demandas de amparo. Así, de concurrir aquella, la cuestión sería simplemente de valoración de la prueba (realmente existente), por parte, en exclusiva, de la jurisdicción ordinaria; mientras que de darse el segundo en una sentencia condenatoria sí habría tema propiamente constitucional, de competencia de la alta instancia. Pero ocurre que la fórmula «mínima actividad probatoria» ha desbordado, con harta impropiedad, ese contexto y ha pasado a ser, en abundantísima jurisprudencia, la fórmula utilizada para referirse a la prueba de cargo apta para fundar una condena. Impropiamente, porque, para legitimar una resolución de esa clase, la prueba de cargo nunca debería ser mínima sino suficiente, esto es, la necesaria, a tenor del supuesto, para tener por bien acreditada la veracidad de la hipótesis acusatoria. Claro que el nivel de exigencia en la materia puede dar vuelcos insospechados. Así, mientras ha existido consenso en torno al criterio de la «mínima actividad probatoria» para condenar, recientemente, el ministerio público ha dado el paso hacia una estupefaciente opción de máximos, al fijar la calidad de los datos incriminatorios que habilitarían para iniciar una investigación judicial; opción revalidada por la Sala Segunda del Tribunal Supremo. Fue en el asunto de la posible obtención fraudulenta de un máster universitario por parte del líder del Partido Popular, Pablo Casado, en el que, la solicitud de apertura de la causa contra él, como aforado, no llegó a prosperar. Luego de que el fiscal hubiera argumentado con la inexistencia de «indicios incontestables» de delito - es decir, indiscutibles o incuestionables, según el Diccionario de la RAE— ahora necesarios, ¡ya en ese momento preliminar! Una nueva categoría de indicios, en rigor, diríase que acuñada ad hoc, cuando se sabe bien que la relativa ambigüedad es, precisamente, una condición que suele acompa- 
a la que solo cabe llegar en virtud de una valoración, primero analítica y después de conjunto, de los datos integrantes del cuadro probatorio. Esta, en un momento posterior en el orden lógico, al que no es posible acceder per saltum. Por la elemental razón de que no se trata simplemente de ver si existió prueba, sin más — pues siempre se habrá puesto en juego algún medio_- , sino de comprobar si existió prueba dotada, en concreto, de alguna aptitud acreditativa.

Sí será, en cambio, susceptible de apreciación como desde afuera, el supuesto de vacío probatorio derivado de la consideración de una prueba como aquejada de inconstitucional ilicitud en su obtención. Por ejemplo, el de un registro ilegítimo por falta de autorización judicial — circunstancia de fácil comprobación- en el que toda la prueba de cargo estaría constituida por el resultado del mismo y la posible declaración judicial al respecto de quienes, irregularmente, lo practicaron.

Por tanto, y en realidad, decir in dubio pro reo es solo una forma de designar a la presunción de inocencia, o, si se quiere, a un momento de operatividad, aquel en el que la duda obliga a absolver.

Ya, en fin, y en contra de lo que con frecuencia ocurre, yo no llamaría nunca «interina» ${ }^{34}$ a la presunción de inocencia, porque el vocablo expresa o sugiere la idea de una provisionalidad esencial u ontológica, de una existencia a término, llamada necesariamente a concluir en algún momento. Y no es, en absoluto, el caso.

\section{5. ¿ELEMENTOS DE PRUEBA SUSCEPTIBLES DE APRECIACIÓN EXCLUSIVAMENTE SENSORIAL?}

Hay muchas sentencias de la sala Segunda del Tribunal Supremo en las que se lee que «en la valoración de la prueba directa [hay] un primer nivel dependiente de forma inmediata de la percepción sensorial, condicionado a la inmediación y por tanto ajeno al control en vía de recurso». Tal es aquel en el que discurriría la llamada prueba «directa». Mientras existe — se dice- «un segundo nivel, necesario en ocasiones, en el que la opción por una u otra versión de los hechos no se fundamenta directamente en la percepción sensorial derivada de la inmediación, sino en una elaboración racional o argumentativa posterior, que descarta o prima determinadas pruebas aplicando las reglas de la lógica, los principios de la experiencia o los conocimientos científicos...». Este modo de operar sería el propio de la prueba indirecta o indiciaria.

En el planteamiento del que se hace eco esta línea jurisprudencial, el segundo tipo de prueba, la de indicios, desprovista de la virtualidad de la primera por la precarie-

\footnotetext{
ñarlos. Y cuando, además, los aquí concurrentes, si no incontestables, sí estaban dotados prima facie de verdadera consistencia. Al extremo de que, en algún caso gemelo, han producido justamente el efecto contrario de apertura de la causa, sin oposición del fiscal; cierto que en otra instancia y sin que mediase aforamiento. $Y$ de que creo poder afirmar que no conozco, ni creo que exista, un caso en el que algún representante del ministerio público haya actuado con semejante nivel de exigencia.

34 Son múltiples las sentencias de todas las instancias en las que se habla de la "presunción de inocencia» como «verdad interina de inculpabilidad». También se la califica de "provisional».
} 
dad de su eficacia convictiva, llevaría asociado, incluso, un cierto déficit de legitimidad, que haría necesario justificar su uso. Tanto es así, que no faltan sentencias, de diversa procedencia, en las que se argumenta que el recurso a la misma solo obedece al hecho de que, «si la prueba indiciaria no tuviera virtualidad incriminatoria», «se crearían amplios espacios de impunidad».

En definitiva, la prueba llamada indiciaria sería la vía de acceso a un conocimiento de clase $B$, a cuyo empleo habría que resignarse por esa consideración de pragmatismo defensista. O, lo que es igual, no será un medio probatorio de gran calidad, pero la relevancia del fin aludido, autorizaría a «hacer de la necesidad virtud».

Lo que subyace a ese modo de razonar es una grave confusión acerca de la calidad de conocimiento que permite el proceso penal, que no es sino un saber sobre hechos pasados al que solo cabe llegar por comprobación. Esto es, haciendo uso de la misma clase de recursos cognoscitivos que (porque no existen otros), son los que se emplean en la obtención de conocimiento empírico ${ }^{35}$.

Así las cosas, recogiendo una afirmación de Pagano (2002: 98), lo cierto es que en el proceso penal todas las pruebas son indiciarias, porque aquello que se trata de probar, como perteneciente al pasado (de haber existido), nunca podría ser objeto de la directa percepción por el juez. Es por lo que los resultados de prueba, sea cual fuere el medio de que procedan, presentan en esto una afinidad esencial en lo relativo a su naturaleza y efectos, con la clase de conocimiento que propician.

Todo lo más, como escribe Ferrua (2017: 64-65), la diferencia radicará en que podrán decirse directas aquellas pruebas en las que, «entre la proposición probatoria y la proposición a probar no se interponen proposiciones intermedias». Por eso, prosigue, «la prueba indirecta constituye una combinación de dos o más pruebas que se disponen en secuencia: la proposición probada de la llamada prueba directa se convierte en premisa probatoria con respecto a una nueva y diversa proposición a probar».

En materia de prueba siempre hay que ir de un dato a otro. Un paso que concurre también en la testifical, donde, como se sabe, es imprescindible transitar del hecho de la declaración y sus particularidades al hecho declarado. Y, según se ha visto, esto después de haber realizado algunas valoraciones intermedias sobre la atendibilidad de la fuente de prueba, la consistencia de lo aportado por ella, y la coherencia o falta de coherencia con otros datos de distinta procedencia.

Por eso, la necesidad de revisar un tópico tan arraigado como el consistente en la atribución del carácter de directa por antonomasia a la del testigo presencial, que, se ha dicho en ocasiones, pondría al juez en contacto asimismo directo con los hechos.

35 En la materia, cfr. GonzÁlez LAgier (2005: 117 ss.). Allí se lee algo que, incomprensiblemente, no se tiene en la mínima consideración en el planteamiento que se cuestiona: «Percibir no es recibir pasivamente estimulación: es seleccionar, formular hipótesis, decidir...» (p. 28). Algo ya conocido por Montaigne (1985: I, cap. XXVI, 205), cuando, citando a Epicarmo, escribía "que es el entendimiento el que ve y oye». 
Esto, en virtud del contacto personal (sensorial), favorecido por la inmediación. Un contacto, por ello, privilegiado y exclusivo. Fuente de una experiencia irrepetible y, por lo mismo, blindada a la posible apreciación crítica en otra instancia, que es lo que haría intangible a la fijación de los hechos por la sentencia de primer grado dotada de semejante fundamento ${ }^{36}$.

Se trata de una visión que simplifica en extremo la complejidad del modo de ser real de ese medio de prueba, cuya valoración ha de desdoblarse, ineludiblemente, en dos juicios, estrechamente relacionados: uno sobre el declarante, y otro sobre lo declarado en sí mismo como discurso (coherencia) y en lo relativo a su contenido, en relación con lo aportado por otros medios. En efecto, porque la testifical es una clase de prueba con la que ha de procederse por pasos: la audición del testigo; la valoración de su atendibilidad como tal; y la consideración del contenido de sus manifestaciones, en el marco general del conjunto de las adquisiciones probatorias ${ }^{37}$.

De esos tres pasos, la mayor dificultad se concentra en el segundo, en el que deberá considerarse si el declarante se ha pronunciado con sinceridad (tendría o no motivos para faltar a la verdad; mantiene o no lo dicho en anteriores momentos de la causa). También — junto a la naturaleza, muy posiblemente traumatizante de lo presenciado, y por eso inductora de estrés; la duración de esa secuencia y el tipo de relación con ella; así como el tiempo transcurrido desde entonces, entre otras circunstancias-, tendrá mayor o menor relevancia otra cuestión: la relativa a la capacidad de percepción y la calidad de la memoria del deponente. Con la particularidad de que, algo no siempre sabido o tomado en consideración, la actualización del recuerdo es una actividad compleja. No es un acto, sino un proceso. Y las distorsiones o desviaciones pueden producirse en alguno de los distintos momentos en los que aquella se articula. Por cierto, según STERN, con preocupante facilidad, porque a su juicio: «el recuerdo defectuoso no es la excepción sino la regla» ${ }^{38}$.

La jurisprudencia de la Sala Segunda del Tribunal Supremo ha tratado de introducir algunos criterios de racionalización en la aproximación judicial al testimonio. Son los de: «ausencia de incredibilidad subjetiva», "verosimilitud» y "persistencia en la incriminación», que comparecen en infinidad de sentencias de todas las instancias, en materia penal. Estas pautas, tomadas a veces indebidamente, cual si se tratase de criterios de prueba legal ${ }^{39}$, tienen solo un valor muy relativo. En efecto, la falta de

36 De ese tópico modo de concebir la inmediación me he ocupado en ANDRÉs IBÁÑEZ (2003, y 2015: 272 ss.).

37 Cfr. al respecto, de Paula Ramos (2019: 166 ss.).

38 Cit. por Cataldo de Neuburguer: (2000: 37). Cfr. también Mazzoni (2010 y 2019); y Diges Junco (2016).

39 Me refiero a ciertos usos presididos por el automatismo, en virtud de un razonamiento falaz de este tenor: Concurren: la abstracta verosimilitud del relato, más la ausencia de un móvil espurio (apreciado en conciencia), más el mantenimiento invariable de la misma versión, ergo lo declarado se ajusta a lo efectivamente acontecido. Así, una sentencia, de estos años, de una Audiencia Provincial, razonaba: "Jurisprudencia reiterada del Tribunal Supremo concede valor suficiente para desvirtuar la presunción de inocencia», a lo manifestado por un testigo ajustándose a estos requerimientos. 
presupuestos para su aplicación podrá servir —en negativo— para desestimar el testimonio en sí mismo manifiestamente inverosímil, autocontradictorio o movido por móviles espurios. Pero es obvio que el relato de una situación imaginaria, bien construido y hábilmente expuesto, podría perfectamente ser presentado como veraz y pasar por tal, después de haber sido mantenido sin alteración en los distintos momentos procesales. Y se sabe asimismo por experiencia (clínica y también jurisdiccional) que hay personas que atribuyen a otro la realización de una conducta punible inexistente, sin propósito de perjudicarle, solo como consecuencia de un error de percepción o incluso debido al padecimiento de algún tipo de trastorno. Y, además, podría darse igualmente la circunstancia de que alguien, aun odiando, dijera realmente la verdad al poner a cargo de otro la ejecución de una conducta punible.

En consecuencia, no es que el contenido de una testifical de cargo que supere ese triple filtro deba ser tenido como válidamente inculpatorio. Lo único que cabe sostener es que un testimonio que no lo hiciera debería ser desestimado a limine como medio de prueba; mientras que, en el caso contrario, resultará atendible en principio, y, por tanto, estará justificado — en un segundo momento- entrar en el análisis de su contenido para confrontar sus aportaciones con las de otra procedencia, como forma de evaluar la calidad de los datos.

\section{LA DEL TESTIGO-VÍCTIMA: ¿UNA PRUEBA PRIVILEGIADA?}

Hay, todavía, algo que confiere mayor relevancia negativa al uso de estos criterios. $\mathrm{Y}$ es que, en al caso del (generalmente la) testigo-víctima ${ }^{40}$ de agresiones sexuales, suele argumentarse que es necesario atribuir un especial valor convictivo a su testimonio porque, de otro modo, quedarían impunes conductas de suma gravedad, que habitualmente se producen en la clandestinidad. El argumento, reiterado en no pocas sentencias (y con raíz en alguna de la Sala Segunda del Tribunal Supremo) es «que nadie debe padecer el perjuicio de que el suceso que motiva el procedimiento penal se desarrolle en la intimidad de la víctima y del inculpado, so pena de propiciar situaciones de incuestionable impunidad».

La especiosidad del razonamiento no puede ser más clara, puesto que de ese «nadie» se excluye al imputado, amparado por su derecho a la presunción de inocencia, que aquí se relativiza, se degrada, sin más, en su perjuicio. El modo de discurrir recién ilustrado implica una recuperación del (nunca abolido) dogma inquisitivo, duramente denostado por BECCARIA y FILANGIERI: «In atrocissimis leviores conjecturae sufficiunt, et licet judici jura transgedi». Un criterio, según el primero (2011: 135), «dictado por la más cruel imbecilidad»; para el segundo (2018: I, 659 y nota), «regla

40 En este punto es conveniente señalar la existencia de casos en los que la condición de víctima es ya patente desde el momento mismo de la denuncia, por la concurrencia de estigmas o síntomas inequívocos que informan, por ejemplo, de la existencia del atentado contra la libertad sexual. Pero, cuando esto no suceda, en rigor, tendría que hablarse de denunciante, hasta tanto resulte acreditada la realidad de la propia agresión y su padecimiento. 
absurda» que «ha sacrificado a la imbecilidad de [... los] jurisconsultos a un número infinito de inocentes»; y que, para Constant (1989: I, 250), vendría a significar que "cuanto más grave es una acusación, es mucho más superfluo examinarla». Un criterio aberrante porque la valoración de un elemento de prueba no puede hacerse depender de un estado de opinión, ni de la gravedad del delito, ni tampoco de la demanda social de represión de determinadas conductas, por más graves que estas sean. Pero lo cierto es que cada época tiene sus emergencias, de ahí que aquel no acabe de abandonar el campo. El derecho a la presunción de inocencia como regla de juicio, goza de una vigencia absoluta y no condicionada ni condicionable, y requiere que la condena tenga como fundamento la acreditación del delito y su autoría con certeza práctica, alcanzada como fruto de un examen del material probatorio presidido por la racionalidad, que se exprese en un fallo suficientemente justificado en todos sus extremos relevantes. Que es por lo que no cabe hablar de pruebas privilegiadas ${ }^{41}$ en su calidad convictiva, sin que se produzca una grave degradación de aquel. En efecto, pues la condición, por principio, de testigo privilegiado de alguien, determina la degradación de la presunción de inocencia del afectado por su testimonio inculpatorio. Algo inaceptable, aun siendo una evidencia que hay, y no dejará de haber delitos que, por las circunstancias en se cometen, depararán, inevitablemente, un plus de ventaja para sus autores, que será un, también inevitable, plus de impunidad: y sería aberrante postular un derecho probatorio especial para esta clase de supuestos.

\section{ACERCA DE LA CORROBORACIÓN}

Para esa clase de testifical, la del testigo-víctima, a veces, solo a veces, se exige - y, por lo general, tímidamente, porque de otro modo esa perseguibilidad reforzada de los delitos en régimen de clandestinidad no se lograría — la existencia de alguna corroboración externa.

41 Aquí resulta inevitable hacer referencia a una corriente que — con pretensiones de innovación y de progresismo! - se está abriendo paso en la jurisprudencia de la Sala Segunda del Tribunal Supremo, en sentencias sobre casos de la que se conoce como violencia de género, como la n. ${ }^{\circ}$ 282/2018, de 13 de junio (ponente MAGro SERVET), donde puede leerse: «la víctima se encuentra procesalmente en la situación de testigo, pero a diferencia del resto de testigos, es víctima y ello debería tener un cierto reflejo diferenciador desde el punto de vista de los medios de prueba, ya que la introducción de la posición de víctima en la categoría de mero testigo desnaturaliza la verdadera posición en el proceso penal de la víctima, que no es tan solo quien "ha visto" un hecho y puede testificar sobre él, sino que lo es quien es el sujeto pasivo del delito y en su categorización probatoria está en un grado mayor que el mero testigo ajeno y externo al hecho, como mero perceptor visual de lo que ha ocurrido». No es precisamente un modo diáfano de razonar, no inusual en el mismo ponente, que, por ejemplo, tiene escrito: «Los hechos declarados probados deben ser analizados bajo las circunstancias de la concurrencia de elementos concurrentes de distinta naturaleza que es preciso escindir para deducir de su conjunto la ajustada respuesta jurídica que del orden jurisdiccional penal se desprende de la prueba practicada en el plenario» (Audiencia Provincial de Alicante, sentencia n. ${ }^{\circ} 334 / 2003$, de 21 de junio). 
Esta exigencia, como se sabe, tiene también un ámbito privilegiado de aplicación en la valoración de la declaración heteroinculpatoria del coimputado ${ }^{42}$, y por dos razones: que la vigencia del derecho a no decir la verdad, elimina la (ciertamente tenue) constricción a ser veraz de aquél, y que, al mismo tiempo, la del nemo tenetur se detegere limita las posibilidades de interrogación y la eficacia del examen contradictorio, por tanto.

Pero ocurre que, en materia de corroboración, el avance que esta exigencia podría suponer resulta inmediatamente rebajado, en incorrecta aplicación de un criterio tomado de la jurisprudencia del Tribunal Constitucional. En efecto, este exige regularmente lo que denota como «una mínima corroboración». Pero solo lo hace sirviéndose de este dato como indicador para la determinación de la propia competencia. Dicho de otro modo, de existir esa «mínima corroboración» habría prueba valorable de otra fuente. Y así, a tenor del criterio de la misma instancia, ya examinado, en materia de presunción de inocencia, en tal caso faltaría materia constitucional como precondición de acceso al recurso de amparo, y la cuestión debería permanecer en el ámbito de la jurisdicción ordinaria.

Mas ocurre que el criterio que, en el caso del Tribunal Constitucional, podría servir para que este administre su propia competencia, en el marco jurisdiccional ordinario no puede, en modo alguno, ser usado como parámetro para calibrar la suficiencia de la prueba de cargo aportada por el testigo-víctima o por el coimputado.

En efecto, porque el verbo corroborar denota la acción consistente en reforzar la afirmación que ya tiene apoyo en ciertos datos de determinada procedencia, con otros de origen diverso. Y fuerza es fuerza convictiva, algo que solo pueden transmitir los datos que gocen de determinada aptitud, es decir, aquí, los dotados de verdadera calidad informativa de cargo. Y sabido es que, en este terreno, la adición de un indicio o indicador débil a otro u otros del mismo carácter no lo refuerza, sino que produce el solo resultado de la mera concurrencia de debilidades.

Corroborar es, pues, reforzar la veracidad de un aserto relativo a ciertos hechos, mediante la aportación de datos atendibles de una fuente distinta. Por tanto, el elemento de corroboración será un dato de contenido empírico, suficientemente acreditad, distinto de los que integran la imputación, por tener un alcance más reducido (no la cubre enteramente), por su fuente (otra distinta, pero que interactúa con aquel y pertenece al mismo contexto de acción.

O sea, corroborar es probar, pero no directamente la acción (principal) objeto de la deposición inculpatoria del testigo-víctima o de la heteroimputación del coimputado, lo que haría estas superfluas, sino otro dato de hecho relacionado con aquella de una forma tal que, en términos de experiencia, abonaría la certeza de que, en efecto, tuvo lugar de una determinada manera. Por eso, sirve para reforzar la convicción de que la primera se habría producido realmente en los términos que dice el que imputa.

42 Para una útil aproximación a esta figura y sus implicaciones, cfr. BEVERE (1993). 
El elemento de corroboración debe recaer, no sobre la atendibilidad del declarante, sino sobre lo declarado por él, sobre circunstancias que relacionarían al destinatario de la imputación o de la coimputación con el hecho imputado. Esto es, sobre aquello cuya veracidad se trata de confirmar, para que pueda entenderse acreditado.

Por tanto, la valoración de esta prueba compleja tiene que producirse en tres tramos, los relativos: a la credibilidad del testigo-víctima o del coimputado que imputa a otro; a la consistencia interna de la declaración inculpatoria; y a la existencia de elementos de corroboración de otra fuente.

En fin, el elemento de corroboración debe estar referido, no genéricamente al destinatario de la imputación, sino al mismo en relación con el hecho objeto de esta. Por tanto, no se trata de contar (como muchas veces se dice) con datos vagamente relativos a circunstancias de las llamadas "periféricas», sino que, del mismo modo que la información inicial, la que se cruce con esta debe servir para conectar, indirecta pero eficazmente, al imputado con la acción delictiva que se le atribuye.

\section{SOBRE EL VALOR PROBATORIO DE LAS ACTUACIONES DE LA INSTRUCCIÓN}

Otro asunto que creo interesante examinar críticamente: el del valor o falta de valor probatorio del resultado de las actividades propias de la instrucción cuando son trasladadas al juicio oral.

Reiteradísima jurisprudencia de todas las instancias, a partir de la del Tribunal Constitucional y la del Tribunal Supremo, consideran auténticas pruebas solo a las practicadas en el juicio oral, con inmediación y contradicción. Las diligencias de investigación llevadas a cabo con anterioridad, fuera de esa fase, no tendrían en sí mismas la consideración de pruebas; pero, excepcionalmente, podrían valer como tales $^{43}$. Esto en el caso de que, practicadas en su momento con las formalidades de la ley, fueran reproducidas en el juicio, mediante lectura, con lo que, se dice, podría hacérseles objeto de debate contradictorio.

Así, resultarían dos modalidades de contradicción: la genuina, que es la que tiene lugar de manera actual en la vista e incide directamente sobre los actos de producción de la prueba; y la ficta, de carácter subsidiario, representada por el acceso al juicio oral, como documental, de diligencias de investigación practicadas en un momento

43 Esta cuestionable tendencia tuvo una versión extrema en alguna jurisprudencia de la Sala Segunda del Tribunal Supremo, que acabó dando lugar a un acuerdo de pleno (aprobado por mayoría), de fecha 28 de noviembre de 2006 decidiendo que las declaraciones válidamente prestadas ante la policía pueden ser objeto de valoración por el tribunal, previa su incorporación al juicio oral en alguna de las formas admitidas por la jurisprudencia». Se dijo bien «jurisprudencia», al tratarse de un criterio abiertamente contra legem, sin apoyo legal, por tanto (art. 297 Ley de E. Criminal), luego descalificado por el Tribunal Constitucional (sentencia de amparo n. ${ }^{\circ}$ 68/2010), que, sic transit, no mantendría este criterio durante mucho tiempo, a tenor de sentencias como la de amparo de n. ${ }^{\circ}$ 165/2014. De estos recusables usos del atestado me he ocupado en ANDrÉs IbáÑEz (2015: 321 ss.) 
anterior, fuera de él, por tanto. De este género son las lecturas de actuaciones del sumario permitidas por el art. 730 de la Ley de E. Criminal, «cuando por causas independientes a la voluntad [de las partes] no puedan ser reproducidas en el juicio oral».

También el art. 714 de aquella permite recurrir a la lectura de diligencias del sumario, para confrontar "al testigo" con declaraciones producidas en esa otra fase procesal, divergentes de las realizadas en el juicio ${ }^{44}$.

En algún caso, el del imputado que, tras de haber declarado (normalmente en sentido inculpatorio) en la policía, se negase a declarar en el juzgado y en la vista, ese recurso a la lectura se ha extendido (en régimen rigurosamente extralegal) al atestado, con el complemento de la declaración los agentes que actuaron en comisaría, llamados (obviamente) a manifestar, que lo dicho ante ellos, en su momento, había sido trascrito con rigurosa fidelidad ${ }^{45}$.

Pues bien, no es infrecuente que, por efecto de la utilización de alguno de estos expedientes, en las sentencias se hable de contradicción, como si esta se hubiera producido de forma real y actual. Como si leer en el juicio la trascripción de la declaración sumarial pudiera equivaler a la audición del declarante. Como si la audición en juicio de los policías que suscriben la declaración del imputado que figura en el atestado, equivaliese a escuchar a este, directamente interpelado.

Cuando se argumenta de este modo, se incurre en una grave confusión de planos, el jurídico y el epistémico de la actividad probatoria. Con olvido de que no todo lo que cumple los requerimientos (formales) del primero satisface plenamente las exigencias del segundo. Esto en el mejor de los casos, porque en el aludido supuesto de la ratificación policial de una diligencia del atestado, faltaría incluso la primera exigencia.

Pues bien, aquí no se trata de negar todo o cualquier valor al expediente de la lectura de lo aportado por anteriores diligencias judiciales, debidamente documentadas, máxime cuando se diera en circunstancias de una objetiva imposibilidad de tener presente al declarante en la vista. Lo que se cuestiona es la pretensión de que la vali-

44 En este punto, hay que señalar que, donde la ley dice «sumario» (es decir, actuación judicial) y "testigo», la jurisprudencia ha entendido también atestado (o sea, actuación policial) e imputado, enmendando la plana al legislador. Asimismo, ha interpretado que el juzgador, además de poner de relieve el contraste entre declaraciones, podría optar por dar valor probatorio a las manifestaciones producidas antes y fuera del momento del juicio. Reescribiendo, por tanto, en perjuicio del imputado, el precepto de referencia.

45 Es lo sucedido en algunas sentencias de la Sala de lo Penal de la Audiencia Nacional en casos de terrorismo, cuando, ante el silencio del acusado en el juicio, el fiscal propone como prueba la declaración de los agentes que recibieron su declaración en comisaría. El resultado es que su manifestación en la vista en el sentido de que lo documentado por ellos en aquel momento es lo efectivamente declarado por el primero, lleva al tribunal a transustanciar esta deposición policial en confesión autoinculpatoria del imputado, producida, además, de forma contradictoria en el juicio, con todas las garantías (!). Con este modo de operar no es que se violente de forma abrupta el constitucional derecho del acusado a guardar silencio, sino que se ignora la condición legal de mera denuncia del atestado. Y se hace un uso francamente inaceptable de (muy peculiares) testigos de referencia. 
dez jurídico-formal del acto permita hablar de contradicción sin mayores matizaciones, y que pueda operarse como si esta se hubiera dado con inmediación real y actual.

En efecto, pues desde el punto de vista de la apreciación probatoria, no puede atribuirse el mismo valor a lo obtenido en el directo examen contradictorio de un declarante que a lo que este hubiera podido manifestar en algún otro momento (generalmente, sin contradicción), y que ahora carece de otra existencia que la textual.

A Platón (2010: 275b, 835) se debe una reflexión sumamente interesante en este contexto, puesta en boca de Sócrates, en el Fedro: las palabras escritas no saben responder, $\mathrm{y}$ «si se les pregunta algo, responden con el más altivo de los silencios».

Por eso, el cumplimiento de los trámites legales, permitirá al juez-jurista introducir en el cuadro probatorio el elemento de prueba aportado a través de esa interlocución ficticia. Pero el juez-operador racional deberá adecuar su valoración atendiendo a ese déficit de interlocución. Pues, mientras la contradicción real puede ser una garantía efectiva de cierta calidad epistémica de los datos adquiridos en el examen de una prueba personal presidido por ell, el cumplimiento de determinadas formalidades legales sustitutivas no tiene por qué serlo.

\section{LA LLAMADA 'TEORÍA’ DE LA CONEXIÓN DE ANTIJURIDICIDAD O (CASI) TODO VALE}

Hay, en fin, otro (muy grave) tópico de nuestra jurisprudencia, que me gustaría examinar aquí. Es el que gira bajo el rótulo que acaba de trascribirse: «teoría de la conexión de antijuridicidad» ${ }^{46}$.

Es una implicación —ya se ha dicho- del principio de presunción de inocencia, correctamente interpretado en el contexto de la actual disciplina constitucional del proceso como regla de juicio, que la única prueba apta para destruir la presunción de inocencia es la legitimamente obtenida. Lo prescribe el art. 11,1 de la Ley Orgánica del Poder Judicial, cuando priva de efecto a las que lo hubieran sido, «directa o indirectamente, violentando los derechos o libertades fundamentales»; incorporando a nuestro ordenamiento las «limitaciones autoimpuestas al conocimiento» de que hablara BELING (2009: 6); destinadas a preservar «la integridad constitucional» Aмвоs (2009: 61), mediante una adecuada y coherente jerarquización de los principios y valores en presencia.

El planteamiento fue acogido - diría que sin particular entusiasmo- por los Tribunales Supremo y Constitucional, hasta la sentencia de este último n. ${ }^{\circ} 81 / 1981$, que introdujo un cambio radical en la inteligencia del precepto, al decidir que el desvalor asociado a la vulneración de alguno de esos derechos o libertades fundamen-

46 Para una aproximación crítica al asunto, entre otros, cfr. Díaz Cabiale-Martín Morales (2001), Miranda Estrampes (2004: en particular 129 ss.), Martínez García (2009) y Andrés IbáÑEZ (2015: 332 ss.). 
tales en la adquisición de una prueba, no tendría por qué acompañar necesariamente a la información de cargo obtenida de ese modo ilegítimo, en todos los momentos del proceso en los que pudiera operar. Según esto, dadas las particularidades del caso y algunas del contexto, la pérdida de efectos por razón de la antijuridicidad, podría quedar confinada de manera exclusiva en la actuación infractora original, sin extenderse dentro de la causa al contenido de otros actos de prueba sobre el mismo objeto, por más que, desde el punto de vista le la causalidad natural, pudieran estar relacionadas con ella.

Para decidir si —en el planteamiento jurisprudencial a examen - la antijuridicidad debiera o no rebasar este límite, habría que tomar en consideración, desde el punto de vista interno, la entidad de la garantía menoscabada y la forma en que lo hubiera sido, junto con las características y el resultado de la vulneración. Y, en una perspectiva externa, tendría que valorarse la necesidad de tutela del derecho fundamental en el caso.

A tenor de tales presupuestos, cabrá que la información de cargo obtenida mediante una intervención ilegítima, si hecha valer en un posterior momento del proceso a través de un distinto medio de prueba, pueda, no obstante, operar válidamente, en el caso de resultar este jurídicamente ajeno a aquella primera actuación vulneradora del derecho fundamental. Algo que podría acontecer, por ejemplo, en el caso de que entre una y otro mediase un nexo atenuado ${ }^{47}$; cuando el agente infractor hubiera actuado de buena fe; $y$ en los casos llamados de «descubrimiento inevitable».

En realidad, el planteamiento se limita a la mecánica importación, sin decirlo, de un criterio propio de la jurisprudencia estadounidense; es decir, de un sistema en el que solo se excluirían las pruebas ilícitas (y no por principio, sino en virtud de un ejercicio de ponderación) cuando fuese el único modo de prevenir futuras desviaciones en el proceder de la policía, mediante el conocido como deterrent effect. Pero lo cierto es que la incorporación de tal criterio a nuestro marco jurisprudencial, en la forma en que lo ha sido, no puede resultar más perturbadora, vista la claridad del enunciado legal que rige en la materia, que proscribe la utilización de las pruebas «obtenidas directa o indirectamente» del modo que se ha dicho. «Directa o indirectamente», luego: tertium non datur. $\mathrm{O}$, lo que es lo mismo, en todo caso.

Falaz es también la distinción de una conexión natural de otra jurídica en la transmisión, dentro de la causa, de la negativa connotación de los datos incriminatorios, que es lo que permitiría dar valor a los recuperados mediante una prueba refleja. En efecto, pues en este punto, la ley tampoco distingue, y mal podría hacerlo para deslindar dos tipos de cauce, el natural y el jurídico, en un contexto rigurosamente

$47 \mathrm{Al}$ respecto, es paradigmático el caso del poseedor de un alijo de droga, hallado en un domicilio, por ejemplo, en virtud de una entrada sin autorización judicial y cuando no hubiera mediado flagrancia delictiva, que, llegado el momento de ser oído en la vista, admitiese la realidad de ese hecho. Tengo constancia directa de dos casos en los que, siendo dos los imputados, uno confesó y fue condenado, por la existencia de una prueba de cargo independiente de la original afectada por una contaminación insanable; mientras que el que negó, en ausencia de aquella, pudo beneficiarse de una sentencia absolutoria. 
formalizado, en el que los actos desencadenantes habrían sido realizados por sujetos institucionales, en el ejercicio de su función; y en el que, incluso, el proceso de traslación de datos, de uno a otro momento procesal, se habría producido en "papel de oficio».

Dadas estas circunstancias, la calificación de independiente de la confesión sanatoria a la que acaba de hacerse referencia está aquejada de una insoportable falta de rigor. Ya solo por haber sido hecha en respuesta a una pregunta de la acusación francamente capciosa y fraudulenta (de las prohibidas en el art. 709 de la Ley de E. Criminal). Por otra parte, y aunque esta - que es mucho forzar- pudiera no considerarse tal y se dijera, como se dice, que el confesante en el juicio, en cuanto asistido de su defensor, lo habría hecho con todas las garantías, lo cierto es que las ilegitimidades constitucionales no son reversibles; y menos por la observancia de garantías que no retroact $u$ an y solo tienen un efecto actual y referido al acto sobre el que se proyectan.

A veces se ha argumentado que la droga aprehendida existiría en todo caso. Pero el argumento es aún más pobre, pues lo que se postula no es que el hecho de la ilegitimidad de la incautación convierta la droga en no-droga o en droga legal, sino que el dato de la existencia de la sustancia, por el modo de obtención, no puede pasar el filtro de constitucionalidad, que es lo que le impide acceder al proceso con eficacia.

Así sucede que el Tribunal Constitucional ha hecho algo tan simple y tan impropio como reescribir el art. 11,1 LOPJ, de modo que, donde este decía «no surtirán efecto», ha pasado a decir: «surtirán efecto, salvo que...». Un que, que, prácticamente, nunca o casi nunca se produce.

Y no es lo peor que la alta instancia haya operado de forma tan impropia. Es que ha investido a los jueces y tribunales de la potestad de formar y emitir juicios de mera oportunidad, en situaciones en las que lo que está en juego son, pura y simplemente, derechos fundamentales. Doblemente conculcados, por obra de la jurisprudencia que se contempla.

La razón del modo de proceder aquí cuestionado, es decir, de la decisión de enmendar la plana al legislador, tiene poco o nada de jurídica. En efecto, pues responde al propósito de hacer prevalecer un pragmatismo político-criminal sin principios. Un demoledor (casi) todo vale. Que, en la práctica, supone incentivar, con irresponsabilidad manifiesta, intolerables faltas de profesionalidad policiales, judiciales y del ministerio público.

En efecto, porque cualquiera que goce de una mínima experiencia práctico-procesal, sabe que todas las actuaciones gravemente vulneradoras de garantías y derechos, que conducen a las situaciones de que se trata, podrían (como deberían) haberse realizado, sin problema, conforme a derecho. Pero sucede que, cuando la inobservancia de este no conduce a la inefectividad de los resultados torcidamente perseguidos: ¿para qué el esfuerzo? Si, al fin, vale igual un registro constitucionalmente ilegítimo que uno regularmente producido; si un auto, mero impreso de ordenador con el que 
se estampilla un atestado ${ }^{48}$, puede servir lo mismo que uno artesanal y rigurosamente motivado: ¿para qué la pérdida de tiempo que conlleva la observancia de las correspondientes exigencias constitucionales de garantía?

De este modo, con lo fácil que podría resultar inducir, en el tratamiento de materias tan delicadas, el círculo virtuoso que reclama la legalidad vigente en todos sus planos, se opta por confirmar y reafirmar el círculo vicioso ${ }^{49}$. Profundamente deslegitimador de quienes lo propician con sus actuaciones; pero también del ordenamiento como tal, constreñido a vivir en permanente y contradictorio desacuerdo consigo mismo.

\section{BIBLIOGRAFÍA}

Aguilera de Paz, E., 1924: Comentarios a la Ley de Enjuiciamiento Criminal, Madrid: Editorial Reus. Ajello, R., 1976: Arcana iuris. Diritto e politica nel settecento italiano, Nápoles: Jovene Editore.

Alessi Palazzolo, G., 1979: Prova legale e pena. La crisi del sistema tra evo medio e moderno, Nápoles: Jovene editore.

Амвоs, K., 2009: «Las prohibiciones de utilización de pruebas en el proceso penal alemán», en Ernst Beling, Kai Ambos y Óscar Julián Guerrero, Las prohibiciones probatorias, Bogotá: Temis.

ANDrÉs IвÁNÉEZ, P., 1992: «Acerca de la motivación de los hechos en la sentencia penal», en Doxa, 12: 257-299.

- 2003: «Sobre el valor de la inmediación. (Una aproximación crítica)», Jueces para la Democracia. Información y debate, 46, ahora en P. Andrés Ibáñez, Los 'hechos' en la sentencia penal, México: Fontamara, 2005: 191 ss.

— 2006: «Motivación "por delegación” de las decisiones judiciales que limitan derechos fundamentales», inicialmente publicado en Derecho y justicia penal en el siglo XXI, Liber amicorum en homenaje al profesor Antonio González Cuéllar García, Madrid, Colex. También en Íd., P., Cultura constitucional de la jurisdicción, Bogotá: Siglo del Hombre Editores-Universidad EAFIT, 2011: 221 ss.

— 2007a: «"Justicia" de oportunidad: una alternativa no jurisdiccional al proceso penal», en Íd. Justicia penal, derechos y garantías, Lima-Bogotá: Palestra-Temis: 222-238.

— 2007b: "Carpintería de la sentencia penal (en materia de "hechos")», en Poder judicial, n. ${ }^{\circ} 49,1998$; ahora en Íd., En torno a la jurisdicción, Buenos Aires: Editores del Puerto, Buenos: 235 ss.

- 2015: Tercero en discordia. Jurisdicción y juez del estado constitucional, Madrid: Trotta.

Anónimo, 2019: El abogado secreto. Historia sobre las leyes y cómo se quebrantan, trad. cast. de M. Palmer, Madrid: Capitán Swing.

Armenta Deu, T., 2012: Sistemas procesales penales. La justicia penal en Europa y América, Madrid: Marcial Pons.

Beccaria, C., 2011: De los delitos y de las penas, prefacio de P. Calamandrei, texto italiano fijado por G, Francioni, edición bilingüe al cuidado de P. Andrés Ibáńez, Madrid: Trotta.

BeVERE, A., 1993: La chiamata di correo nel nuovo processo penale, Milán: Giuffrè.

Calamandrei, P., 1952: apostilla a F. Carnelutti, "A proposito della tortura», en Rivista di diritto processuale: VII (1 ${ }^{\text {a }}$ parte): 238-239.

48 Cfr. sobre el particular ANDRÉs IBÁÑEZ (2006).

49 Aquí suele invocarse el llamado principio de conservación de los actos y el propósito de evitar las situaciones de impunidad en que se traduciría la declaración de las obligadas ilegitimidades, con su secuela de nulidades. Pero, aparte de que las malas prácticas subyacentes tendrían, en ocasiones, que ser tratadas como delitos, que permanecen impunes, pregúntese el lector por el tiempo que tardarían los distintos operadores (policiales, judiciales y del ministerio público) en acomodar sus prácticas al mejor derecho, si los tribunales Supremo y Constitucional se hicieran realmente firmes en el que debiera ser su papel de exigencia. 
- 1960: Proceso y democracia, trad. cast. de H. Fix Zamudio, Buenos Aires: Ediciones Jurídicas EuropaAmérica.

Carnelutti, F., 1959: Las miserias del proceso penal, trad. cast. de S. Sentís Melendo, Buenos Aires: Ediciones Jurídicas Europa-América.

Carrara, F., 1976a: Programa del curso de derecho criminal, trad. cast. de J. J. Ortega Torres y J. Guerrero Leconte, Bogotá: Temis.

- 1976b: «El antiguo procedimiento penal de Luca», en Opúsculos de derecho criminal, trad. cast. de J. J. Ortega Torres y J. Guerrero Leconte, Bogotá: Temis: 32-51.

De Castro, P., 2009: Defensa de la tortura, Valladolid: Editorial Máxtor.

de Cataldo Neuburger, L., 2000: Esame e controesame nel processo penale. Diritto e psicología, Milán: Cedam.

De Paula Ramos, V., 2019: La prueba testifical. Del subjetivismo al objetivismo, del aislamiento científico al diálogo con la psicología y la epistemología, trad. cast. de L. Criado Sánchez, Madrid: Marcial Pons.

Constant, B., 1989: Curso de politica constitucional, trad. cast. de M. A. López, Madrid: Secretaría General Técnica del Ministerio del Interior.

Devis Echandía, H., 1981: Teoría general de la prueba judicial, Buenos Aires: Víctor P. Zavalía editor.

Díaz Cabiale, J. A. y Martín Morales, R., 2001: La garantía constitucional de la inadmisión de la prueba ilícitamente obtenida, Madrid: Civitas.

Diges Junco, M., 2016: Testigos, sospechosos y recuerdos falsos, prólogo de J. J. López Ortega, Madrid: Trotta.

Fasin, D., 2018, Punire, trad. it. de L. Alunni, Milán, Feltrinelli.

Fernández López, M., 2005: Prueba y presunción de inocencia, Madrid: Iustel.

Ferrajoli, L., 1995: Derecho y razón. Teoría del garantismo pena, trad. cast. de P. Andrés Ibáńez, J. C. Bayón, R. Cantarero, A. Ruiz Miguel y J. Terradillos, Madrid: Trotta.

— 2006: «El derecho penal de enemigo y la disolución del derecho penal», trad. cast. de P. Andrés Ibáñez, en Jueces para la Democracia. Información y debate, 57; ahora en Íd., Escritos sobre derecho penal, edición de Nicolás Guzmán, Buenos Aires: Hammurabi, Buenos Aires, 2014, 2: 153 ss.

Ferrer, J. 2007: La valoración racional de la prueba, Madrid: Marcial Pons.

Ferrua, P, 1992: «Il nuovo processo penale e la reforma del diritto penale sostanziale», en Studi sul processo penale. II Anamorfosi del processo accusatorio, Turín: Giappichelli, pp. 13-42.

— 2012: Il 'giusto processo', Bolonia: Zanichelli, $3^{\text {a }}$ edición.

— 2017: La prova nel processo penale. I Struttura e procedimento, Turín: Giappichelli.

Filangieri, G., 2018: Ciencia de la legislación, trad. cast. de J. Ribera, edición y revisión del texto por L. Prieto Sanchís, con prólogo de D. Ippolito, Madrid: Agencia Estatal Boletín Oficial del Estado.

Florian, E., 1982: De las pruebas penales, trad. cast. de J. Guerrero, Bogotá: Temis.

Gascón Abellán, M., 1999: Los hechos en el derecho. Bases argumentales de la prueba, Madrid: Marcial Pons.

González Lagier, D., 2005: «Los hechos bajo sospecha: sobre la objetividad de los hechos y el razonamiento judicial», en Quaestio facti. Ensayos sobre prueba, causalidad y acción, Lima-Bogotá: Palestra-Temis: $17-52$.

Grevi, V., 1972: Nemo tenetur se detegere, Milán: Giuffrè.

GuZMÁN, N., 2018: «La teoría del estándar objetivo de prueba y el garantismo penal: dos perspectivas antagónicas sobre el proceso penal», en Jueces para la Democracia. Información y debate, 92: 85-99.

Habermas, J., 1998: Facticidad y validez. Sobre el derecho y el estado democrático de derecho en términos de teoria del discurso, trad. cast. de M. Jiménez Redondo, Madrid, Trotta.

IACoviello, F. M., 1997: La motivazione della sentenza penale e il suo controllo in cassazione, Milán: Giuffrè.

Illuminati, G., 1979: La presunzione d'innocenza dell'imputato, Bolonia: Zanichelli,

Verlanga Huerta, F., 1842: Procedimiento en materia criminal, Madrid: Librería de Ríos.

Jаковs, G., 2003: ¿Cómo protege el derecho penal y que es lo que protege? Contradicción y prevención: protección de bienes jurídicos y protección de la vigencia de las normas», trad. cast. de $\mathrm{M}$. Cancio Meliá. Texto mecanográfico de la conferencia impartida en la Fundación Ortega y Gasset de Madrid. 
LucChini, L., 1905: Elementi di procedura penale, Florencia: G. Barbèra editore.

Luzón Cuesta, J. M.: 2000, El recurso de casación penal, Madrid: Colex.

Malatesta, F., 1988: Lógica de las pruebas en materia criminal, trad. cast. de S. Carrejo y J. Guerrero, Bogotá: Temis.

ManduCA, F., 1888: Studii teorico-practici sulla procedura penale, Nápoles: Ernesto Anfossi.

Martínez García, E., 2009: Actos de investigación e ilicitud de la prueba, Valencia: Tirant Lo Blanch.

Mazzoni, G., 2010: ¿Se puede creer a un testigo? El testimonio y las trampas de la memoria, trad. cast. de J. M. Revuelta, Madrid: Trotta.

— 2019: Psicología del testimonio, trad. cast. de A. Moreno, Madrid: Trotta.

MecCarelli, M., 1998: Arbitrium. Un aspetto sistematico degli ordinamenti giuridici in età di diritto comune, Milán: Giuffrè.

Miranda Estrampes, M, 2004: El concepto de prueba ilícita y su tratamiento en el proceso penal, Barcelona, J. M. Bosch Editor: Barcelona.

Montaigne, M., 1985: Ensayos, edición de M. D. Picazo y A. Montojo, Madrid: Cátedra.

Muratori, L., 1794: Defectos de la jurisprudencia, trad. cast. de V. M. de Tercilla, Madrid: Imprenta de la viuda de don Joachin Ibarra.

Nobili, M., 1974: Il principio del libero convincimento del giudice, Milán: Giuffrè.

Pagano, M., 2002: Principios del Código Penal, introducción y notas de S. Moccia, trad. cast. de E. R. Zaffaroni, revisión de M. Rivacoba y Rivacoba, Buenos Aires: Hammurabi.

Pastor, D., 2005: Recodificación penal y principio de reserva de código, Buenos Aires: Ad Hoc.

PizzI, W. T., 1999: Juicios y mentiras, Crónica de la crisis del sistema procesal penal estadounidense, prólogo y traducción de C. Fidalgo Gallardo, Madrid: Tecnos.

Platón, 2010: «Fedro», trad. cast. de E. Lledó, en Íd. Diálogos, prólogo de C. García Gual, estudio introductorio de A. Alegre Gorri, Madrid: Gredos.

Postel, A., 2014: Un hombre al margen, trad. cast. de M. T. Gallego Urrutia, Madrid, Nórdicalibros: Madrid.

Pound, R.: El espiritu del 'common law', prólogo y trad. cast. de J. Puig Brutau, Barcelona: Bosch (sin fecha, pero la del prólogo es 1954).

Prieto Sanchís, L., 2011: Garantismo y derecho penal, Madrid: Iustel.

Ramírez Ortiz, J. L., 2014: «Verdad, proceso y derecho penal. (Interrogatorios en la habitación 110)», en Jueces para la Democracia. Información y debate, 79: 18-38.

Rosoni, I., 1995: Quae singula non prosunt collecta iuvant. La teoría della prova indiziaria nell'età medievale e moderna, Milán: Giuffrè.

SchünemanN, B., 1991: «¿Crisis del procedimiento penal? (¿marcha triunfal del procedimiento penal americano en el mundo?)», trad. cast. de S. Bacigalupo, en Varios autores, Jornadas sobre la "Reforma del Derecho Penal en Alemania», Madrid: Consejo General del Poder Judicial, 49 ss.

Stevenson, B., 2014: Por compasión. La lucha por los olvidados de la justicia en Estados Unidos, trad. cast. de F. López Martín, Barcelona: Península.

TAIBBI, M., 2015: La brecha. La injusticia en la era de las grandes desigualdades económicas, trad. cast. de E. Ayllón, Madrid: Capitán Swing.

TARuffo, M., 1970: Studi sulla rilevanza della prova, Padua: Cedam.

- 2002: La prueba de los hechos, trad. cast. de Jordi Ferrer Beltrán, Madrid: Trotta.

Ubertis, G., 2000: Principi di procedura penale europea. Le regole del giusto processo, Milán: Raffaello Cortina Editore.

Ubertis, G., 2017: Elementos de epistemología del proceso judicial, trad. cast. de P. Andrés Ibáñez, Madrid: Trotta.

Valiante, M.,1975: Il nuovo processo penale. Principi fondamentali, Milán: Giuffré.

Verlanga Huerta, F., 1842: Procedimiento en materia criminal I, Madrid: Librería de Ríos.

Von Beling, E., 2009: «Las prohibiciones de prueba como límite a la averiguación de la verdad en el proceso penal», en Ernst Beling, Kai Ambos y Óscar Julián Guerrero, Las probibiciones probatorias, Bogotá: Temis.

Winslow, D., 2019: Corrupción policial, trad. cast. E. Del Valle, Barcelona: RBA.

Wolfe, T., 1988: La hoguera de las vanidades, trad. cast. de E. Murillo, Barcelona: Anagrama. 
